\title{
INDIGENOUS FORMS AND MATERIALS IN NIGERIAN PAINTING
}

\author{
Johnson Adelani Abodunrin (PhD) \\ Department of Fine and Applied Arts, Ladoke Akintola, University of Technology, Ogbomoso, Nigeria
}

\section{Original Article}

PII: S238315531900002-8

Received: 05 Apr. 2019 Accepted: 20 Jun. 2019 Published: 05 Jun. 2019

Corresponding author's email: jaabodunrin@lautech.edu.ng

\begin{abstract}
Paintings in Nigeria are characterized with various indigenous forms and materials which differentiate it from its counterpart all over the world. Over the years, there have been issues of identifying what makes Nigeria painting in form and content. However, this paper focuses on the highlight of the indigenous forms in Nigeria painting with a view of bringing into bear what constitutes pattern of forms from different geographical sphere of Nigeria. This paper observes the traditional symbols and elements that are found in indigenous Nigeria art forms that are used for the purposes of ethnic identification in Modern Nigeria painting. The study established that there is a wide range of regional artistic forms that are indigenous to Nigerian culture. In traditional paintings in Nigeria, all these regional forms are reflected in our works which the materials are locally sourced.
\end{abstract}

KEYWORDS: Indigenous, Forms, Materials, Painting, Nigeria

\section{INTRODUCTION}

Nigeria is known all over for her artistic heritage. People's culture is expressed through various art forms. Some of Nigeria indigenous arts and craft are: weaving, pottery, calabash decoration, dyeing, leather work, carving, basketry, wall and body painting. Painting during the pre-colonial period was a very unique tradition and cultural practice among the various Nigerian ethnic groups. However, indigenous forms are those features that are originating or occurring within Nigeria geographical space. Nigeria has an artistic tradition that dates back thousands of years; while much of the country's early art had a religious or spiritual significance, many of the traditional arts and crafts evolved over time to include practical and decorative items while many of the local arts and crafts are regional. Indigenous artists have adapted new techniques and materials in parallel with earlier traditional materials and techniques. Indigenous art continues to be a living and growing concern through which indigenous peoples express their beliefs, celebrate their tradition and look to the future [1].

Among the major culture in Nigeria, Yoruba, Hausa, Fulani, Kanuri and Igbo culture, body painting is the most conspicuous forms of indigenous painting that is noticeable and found among women during ceremonial occasions like wedding and religious festivities [2]. Body painting is a style of painting that is as old as tradition of the culture of the Nigerian people. It has different names to different Nigerian groups. It is known in Hausa, Fulani and Yoruba as the laili and Igbo as uli. The materials are usually plant/flower or bark extract of trees which is mixed with some other ingredients like lemon and cloves used to beautify the skin and fingers in artistically wrought patterns, this form of painting is ephemeral in nature and it is done on women during marriage ceremony. In addition, Campbell [3] observes that shrine painting is also an observable feature of painting practice in Yoruba religious activities. Shrine paintings generally unlike the plastic arts of the Yoruba are treated as one of a lesser art. The neglect of painting in the traditional studies could be attributed to gender-centric considerations as it is practiced almost exclusively by women in ephemeral and less permanent nature [3, 4]. The assertion is buttressed by Udechukwu [5] that there are several art forms which because of their transient and perishable nature have received less study. The surface used for this kind of painting is the wall, which gives an elaborate expression on the symbols and meaning of religious images as exemplified in the culture beliefs of the tradition of the people. Also, artists are now using commercially manufactured paints, rather than paints made from local, natural materials. However, they continue to paint the innermost areas of shrines with indigenous paint materials, paralleling the use of plain handwoven cloths (known as jepe) underneath 
successive layers of richly embellished machinewoven cloth panels of Oyo Yoruba masquerades.

Nigeria is a country that parades various architectural building with different forms and embellishment that are peculiar to our indigenous forms [6]. For example, architecture in the northern part of Nigeria is decorated with various symbols such as the northern knot. The Northern knot is another symbolic form found in the Northern part of Nigeria architecture which suggests an emotive symbol of Northern Nigerian power and political identity that was adopted by the region (Figure 1). The symbol was adopted in the 1950s when Nigerian elites were preparing for political independence from Britain. This symbol represents the unity in diversity which encapsulated in the One North philosophy that was used to fight for representation and privileges of Northern Nigeria. This symbol has become unique in arts and crafts objects as an entity for geographical identification of the region. Also, some of the wall paintings and etchings are Quranic verses with an artistic, calligraphic slant. The verses capture the imagination and to elicit aesthetic appreciation, but this is not an end in itself. This symbolic design has been incorporated into various artistic formations in the northern part of Nigeria ranging from architecture, textile, crafts and modern painting.

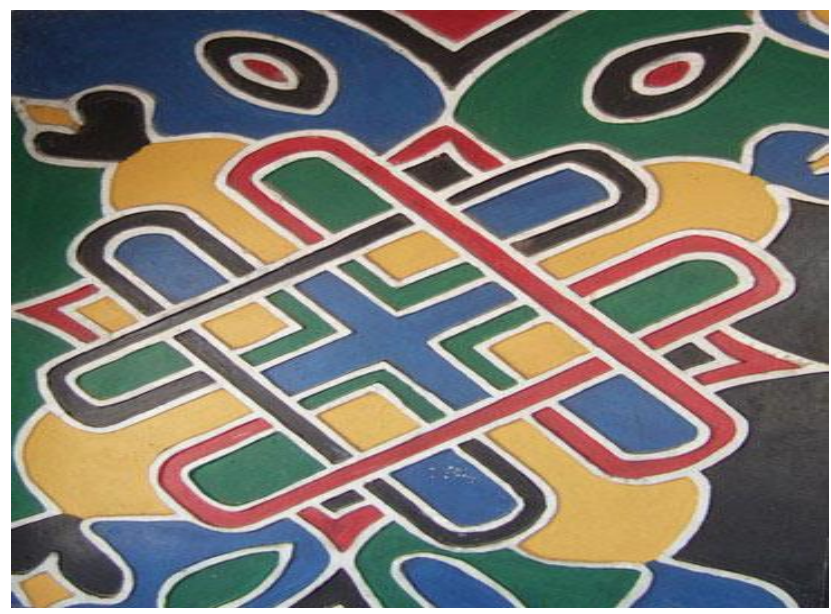

Figure 1. One North (source: author)

Among other things, this paper focuses on the highlight of the indigenous forms in Nigeria painting with a view of bringing into bear what constitutes pattern of forms from different geographical sphere of Nigeria. This paper observes the traditional symbols and elements that are found in indigenous Nigeria art forms that are used for the purposes of ethnic identification in Modern Nigeria painting. Also, the paper established the content of inculcating and adaptation of cultural elements, of theme, motif, patterns and folklores in the various regional paintings. Most of the scholarly works on this subject are directly on ethnic traditions, contemporary Nigerian art and the issue of regional identification of traditional motifs and values, but not on the overview of indigenous forms of painting in Nigeria as a whole.

For example, Okeke [7] traces Uli forms as lgbo penchant to beautify the body and most importantly as a tribute paid to a deity within the context of annual festivals of rededication and thanksgiving centered on the said deity. Okediji [8] described the iconography forms of Yoruba shrine painting as anthromorphic and Zoomorphic which are merely decorative, but are communicative symbols of the people's culture. Ottenberg [9] in his own case, attributed lgbo art forms into human sociability which commonly appeared on the faces, arms, legs and body of females, from girls to senior women and occasionally on the males, as well as the presence of Uli murals on houses and compound walls of lgbo living areas. Abokede [10] focuses on shrine painting in the upper Oke-Ogun area of Oyo State. His work concentrated on function, history and form of painting found in egungun shrine in upper OkeOgun area with no attention to the focus of this paper. Akinwumi [11] observed the state of Nigerian traditional linear art with particular reference from those found on Fulani body art and gourd art, cloth decoration of the Jukun, body and wall painting in the Edo town of Lueleha, Ibibio body painting and scarification, Igbo, Uli and ichi marks; nsibidi script of Cross River culture area and Yoruba shrine wall paintings. Campbell [4] covers several aspects of shrine paintings, which include the art historical documentation of the work, the classification and meaning of colour in Yoruba cosmology, the materials used in the production of shrine paintings. Smith [12] attempted to provide a comprehensive overview of Uli body and mural painting, and how it represents the synthesis of Igbo culture. In addition, the study explores the metamorphosis of Uli art, specifically how it has evolved the skilful of contemporary Igbo artists, both male and female. However, as rich as these scholarly works are, none has focused directly on the indigenous forms in Nigeria as products of image representation in modern painting, the gap which this study filled.

\section{RESULTS AND DISCUSSION}

\section{Indigenous Symbols in Nigeria Painting}


Generally, the forms of Nigeria indigenous painting are part of our history and have served specific purposes in the era of its creation. Such purposes may have been for either traditional or religious activities which defines the culture of such a tribe within Nigeria geography. For instance, the Igbos made bronze ceremonial vessels a part of their cultural heritage while the Yorubas have been known for their poetic and artistic history. They specialized in making sculptures which often represented a deity of some sort. The Hausa-Fulani art is somewhat associated with their daily way of living; such routines as farming and animal rearing. It is however mostly influenced by their religious beliefs and spirituality. In traditional paintings in Nigeria, all these regional forms are reflected in our works which the materials are locally sourced. The materials ranging from raw materials from plants and earth colours are used to depict various cultural themes of painting.

Indigenous forms are characterized with traditional subject, styles and techniques usable within Nigeria space. Nigeria is the populous African nation with several ethic groups which all vary in their socio-cultural affinities. Nigeria art forms from the time immemorial also different in the use of subject, style and material techniques. Indigenous artists in this context are the traditional artists whose their practices have taken into concentration their locality without western interference.

Traditional subject matter in artistic presentation described the focus and the intention of an artist. The physical content that is visually represented in a painting is the subject. The subject in painting could be in form of landscape, still-life, portraits, mural decoration, figural and non-figural composition. The subjects of representation in traditional or indigenous painting are human figures which embodied the vivid image of the Nigerian way of life combined with the magnificent history of the past. One of the major aspects of the subject lies in the fact that they draw their inspiration from the traditional folk heritage of the region. It also includes pictorial symbols such as mysterious animals, deities, gods, goddesses, ancestral deities and spirits. The indigenous painters drew objects, rendering their units rich and multicoloured dominated basically with primary colour in their composition. The paintings produced during this period were derived from traditional Yoruba mythology, deities, as well as, individual fantasies [13].
Artistic style is therefore the product of constant, recurring or coherent visual or conceptual traits. In painting, for example, a style might include characteristic of materials, brush strokes, colour combinations, subject matter, and technique of representation among several other reasons. Style may be associated with an entire culture within a particular time and place with a particular group of artists, with an individual artist and with a particular institution or school over a period of time [14]. Some artists develop a style and stick to it; while others have several styles, either simultaneously or sequentially. The style used by indigenous artists is between abstraction and naturalistic painting. The subjects are often decreasing of the size of objects proportionally with distance, muting of colour and decrease of the precision details. It often characterized by a childlike simplicity in its subject matter and techniques. They explored the world of Yoruba folklore expressions on dreams, nightmares and weird pictorial elements which are difficult to understand because of their surrealistic tendencies. They made use of bright colours, stylized and disjointed figures, as well as unconventional materials. The forms are original, spontaneous and naively created with utter disregard for the depth, space or any expected relationship of motif themes are most times derived from folktales, myths and religious stories. Among the traditional artists among the Yoruba, who have made significant impacts are Twins Seven Seven, Muriana Oyelami, Adebisi Fabunmi, Nike Okundaye, Jimoh Buraimoh.

Uli is the name given to the traditional designs drawn by the Igbo people of Nigeria. It is an art tradition in which simplified linear rendering of form is balanced by an immense understanding of the qualities of both positive and negative space [15]. Uli is an Igbo female body and wall painting tradition from southeastern Nigeria that is based on sinuous abstract forms derived from nature (Figure 2). The Uli rich art tradition has become the signature tune for identifying the Nsukka School of art. The calligraphic nature of Uli art (body painting/ decoration) influenced the products work (Figure 3). The philosophy of application of Uli art form as espoused by Uche Okeke and later supported by Chuka Amefuna, Chike Aniakor and El-Anasui was to intensify the search for Igbo-identity, thereby using the Uli linear forms to depict radical sociopolitical and cultural subject matters.

In the traditional culture of the Igbo, Uli art according to Wills [16] was an art of the women folk. The motifs and symbols or patterns employed in Uli 
body and wall decoration were derived from different aspects of the people environment and world view. Some Uli were abstract with zigzag patterns and concentric circles, while others stood for house hold objects such as bowls, stools, pots, farm tools etc. Many represented animals and birds such as python, lizard, leopard, alligator, lion, monkey, eagle, owl, and kite, etc. or celestial bodies, the crescent moon and star [9]. It is pertinent to note that traditional Uli was employed in many social functions, such as title taking, marriages, memorial services for the dead, harvest rites and ritual performances. This perharps is the reason why Ottenberg [9] says that Uli designs which commonly appeared on the faces, arms, legs and body of females, from girls to senior women and occasionally on the males, as well as the presence of Uli murals on houses and compound walls of Igbo living areas suggest human sociability.

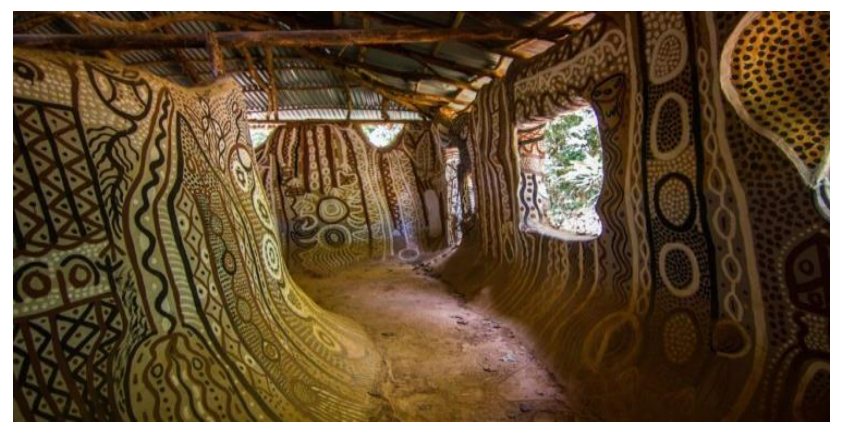

Figure 2. Uli wall painting (Source: grandmotherafrica.com)

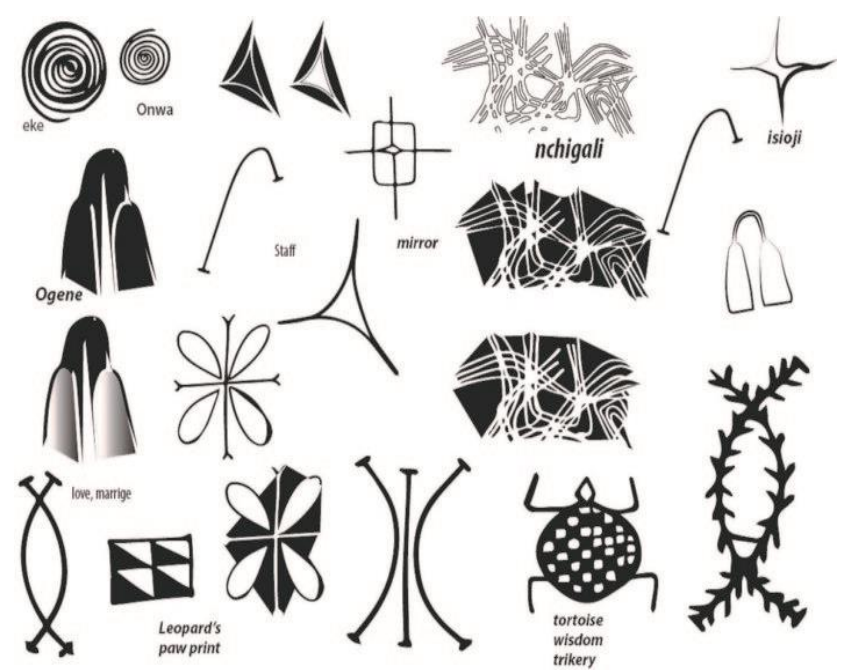

Figure 3. Uli symbol (Source: ezibota.com)

On the other hand, Ona has also played a great role in the works of some of the Yoruba artists (Figure 4). Ona is a Yoruba word that has a wide application. Ona refers to decoration, pattern, ornament, embellishment, design composition, form, plan and motif. Okediji [17] explains the use of Ona for embellishment of traditional sculpture in wood. Such examples are found on decorations on Opon Ifa (Ifa Divination tray) Osa Sango (Sango Axe) Opo (House posts) doors and window carvings. Ona is also noticeable in traditional Yoruba pottery. The Yoruba, generally, like adornment for their body. The sources by which traditional Yoruba artists derived the Ona motifs or pattern are from nature, animals, birds, man-made objects, insects, plants and dreams (Figure 4). The ONA group of artists which crystallise in Lle-Ife in 1989 are united by their aim to incorporate traditional Yoruba decorative motifs in an art of social comment. Members of the ONA group have conducted research into digenous painting and experimented with materials ranging from clay and calabashes to plastic chippings and plastic sheets. The ONA artists are predominantly Yoruba and include Don Akatakpo, Bolaji Campbell, Kindle Filani, Tunde Nasiu, Moo Ogundipe, Tayo Ojomo, Mayo Okedij, Idowu Otun and Tola Wewe [18].

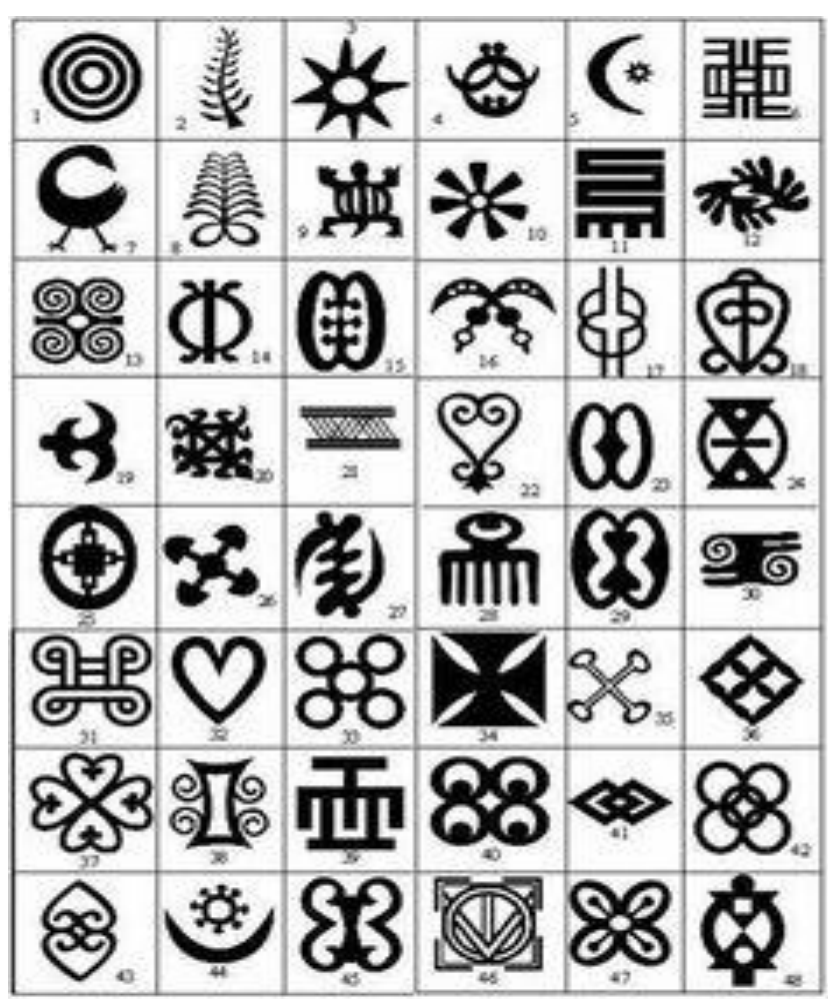

Figure 4. Yoruba traditional symbols (Source: Pinterest.com)

Most of these symbolic forms or icons are reflected and adapted into indigenous painting in Nigeria. However, the study is descriptive examination of the indigenous forms and materials in Nigeria painting by Nigerian artists and it 
unravels what constitutes indigenous forms in Nigeria and how it has been used to achieve indigenous painting that translates into modern styles and techniques.

\section{Artists and indigenous painting in Nigeria}

Artists like their counterparts in different parts of Africa have drawn some of their inspirations from indigenous forms and in so doing have contributed to the creation of an amalgamated national identity, but also continue to give art tradition a life line. The creative and visual talents noticed among many Nigerian artists no doubt is an indication that they have responded to the dynamics of change and continuity. However, indigenous artists are those that have identified themselves in terms of themes, materials, subject matter and techniques that are imbued in our tradition and culture. Most of them did not attend any form of formal education; they learn the trade through apprenticeship. These categories of artists do not believe in Western ideology in the use of forms for artistic practice.

Indigenous paintings are those that drew reference from Nigeria indigenous traditions as those found on Fulani body art and gourd art, cloth decoration of the Jukun, body and wall painting, Ibibio body painting and scarification, Igbo, Uli and ichi marks; nsibidi script of Cross River culture area and Yoruba shrine wall paintings. There are different Schools and ideologies that have developed different experiments and innovations towards Nigerian identity. Members of Osogbo School, founded by Ulli Beier in the earl 1960, have also explored Yoruba spirituality in several media. Leading Osogbo artists include the painter and musician Taiwo Olaniyi, popularly known as Twins Seven Seven, painter and writer Amos Tutuola; and sculptors such as Asiru Olatunde, Adebisi Akanji, Susanne Wenger [19].

Like other aspects of visual arts, themes and concepts which oftentimes associated with the origin and cultural heritage of respective artists have also developed gradually and significantly in modern Nigerian painting. They have become varied, rich and interesting. For instance, Ben Enwonwu painted dancers from various ethnic groups in Nigeria based on their mystic theme. In his paintings, he depicted Yoruba, Hausa, Fulani and Igbo themes, which were mostly geared towards a call for unity and peace in Nigeria [20]. Also, Uche Okeke and his contemporaries took painting to new horizons and experimented with new visual imageries that were derived from traditional African aesthetics from which they created paintings that adequately represented Nigeria, and of course, Africa at large through the use of indigenous elements and forms [21]. Artists from traditional periods until the present time have engaged themselves with beautiful landscapes and seascapes spiced with rich vegetation, alluring and exotic flowers, and cattle rearer, Fulani maids with their milk calabashes decorated and often balanced on their heads, market scenes and so on. Others are in the area of architecture (palaces of traditional rulers: Obas, Obis, Emirs, and Chiefs), festivals (like the Durbar, Eyo, Egungun and Arugungu) mother and child, fishermen as well as other interesting events within Nigeria cultural society [22]. In the early 60 s in the North, some radical students changed their art styles fromcthst ancient traditions and even ignored the realistic approach being taught by expatriates to what could be termed the 'New African' concept. This concept was an admixture of traditions and modernism.

During this period till today, Aristotle created new sensations in their bid to speak in authentic African Odom's in the modern era. Many of these progenitors carried their ideologies to other formal schools or workshops to greater vibrant artistic revolutions. Other artists of the 70 s such as Shina Yusef. Joshua Akande, Dele Jegede, David Dale, Nelson-Cole, Kolade Oshinowo and Gani Odutokun also followed the efforts of the latter, who essentially, being followed by the majority of the recent 'Zaria School' graduates are characterized by elongated of forms, with elegant Northern architecture and human figures. Their themes are usually humane and rendered in discernible images [23]. However the ULI, ONA and the NORTHERN SYMBOLS are charged with significant styles that if continued, could lead to an authentic, modern artistic culture from Nigeria. The adaptations of the indigenous forms in Nigeria could generate remarkable recognition worldwide. The forms are ingeniously employed to serve modern and universal artistic development.

\section{CONCLUSION}

It was established that there is a wide range of regional artistic forms that are indigenous to Nigerian culture. In traditional paintings in Nigeria, all these regional forms are reflected in our works which the materials are locally sourced. The materials ranging from raw materials from plants and earth colours are used to depict various cultural themes. The preponderance of traditional materials gave rise to stylization and modification of forms to 
create themes, which are essentially imbued with naturalistic characteristic. The indigenous painting looks flattened, exaggerated and elongated in a mannerist tendency. The designs are also cubistic and when his subjects are viewed critically, such naturalistic elements are evident. The pattern/motifs are now applied on textiles and used in all sort of visual art such as painting. There are group of artists known as the Ona and Nsukka groups and few artists from the North which are known for reviving the art of indigenous forms in modern times and using art mediums of today like gouche, watercolour, acrylic and so on.

\section{Competing interests}

The author declares that they have no competing interests.

\section{REFERENCES}

[1] Paul S.C. Tacon (2018). From rock art to Contemporary art: Indigenous depictions of trains, planes and automobiles, Australian Archaeology, Vol. 84(3): 281-293 DOI: https://dx.doi.org/10.1080/03122417.2018.1543095

[2] Abodunrin J and Oladiti A (2015). Growth and Development of Styles of Painting in Contemporary Nigeria' IISTE, Research on Humanities and Social Sciences, 5(5): 190-198. Google Scholar

[3] Campbell B (1995). Metaphor of Spiritual Power: The Example of Shrine Wall paintings' in R.O. Rom Kalilu (ed) Powers of Expression and Expressions of Power in Yoruba Art, Bidsol and Associates. Ikeja.

[4] Campbell B (2008). Painting for the Gods: Art and Aesthetic of Yoruba Religious Murals, Trenton, NJ: Africa World Ress. Google Scholar

[5] Udechukwu O (1990). Uli Traditional Wall Painting and Modern Art from Nigeria. An Exhibition held in Lagos and Bayreuth, Western Germany Cultural center. Google Scholar

[6] Oluwaseyi AD, Akande A and Oladiti OA (2018). Heritage Architecture in Ibadan, Nigeria: The House of Adebisi Giwa of Idikan. Journal of Art and Architecture Studies, 7(1): 11-20. Article link ; Google Scholar

[7] Okeke U (1979). History of Modern Nigerian Art. Nigerian Magazine, No. 128-129. Google Scholar

[8] Okediji M (1992). Orisakire Painting School Kurio. Africana: Journal of Art and Criticism, (ed) Okediji, M. Ile-Ife. 1(2): 14-19.
[9] Ottenberg S (1997). New Traditions from Nigeria: Seven Artists of the Nsukka Group (Washington D.C, Smithsonian Institution Press). Google Scholar

[10] Abokede G (2009). Egungun shrine paintings in the Upper Ogun area of Oyo State, ELA: Journal of African Studies, 1(25\&26): 1-25.

[11] Akinwumi T (2006). The state of Nigerian Traditional linear Art at the end of the Twentieth century: An overview, Ela Journal of African Studies, Nos: 19\&20 pp 15-45.

[12] Smith S (2010). Uli Metamorphosis of a Tradition into Contemporary Aesthetic An Unpublished M.A thesis submitted to the College of the Arts of Kent State University. http://rave.ohiolink.edu/etdc/view?acc_num=kent1 267478083; Google Scholar

[13] Ikwuemesi K (1996). Nigeria Art and the Politics of Identity, USO: Nigeria Journal of Art, 1(2): 16-18.

[14] Getlin M (2002). Living with Art, New York. McGraw-Hill Higher Education. Google Scholar

[15] Igboanugo P. (1980). Obiora Udechukwu: Towards Clarity and Essence in Nigeria Magazine; Federal Department of Culture; Lagos. No. 132-133: 6-10.

[16] Wills L (1986). Uli Painting and the Igbo World view African Arts, pp. 62-67. Google Scholar

[17] Okediji M (1989). Contemporary Ife-Art. Ile-Ife: An Exhibition Catalogue, Department of Fine Arts, Obafemi Awolowo University, IIe-Ife.

[18] Adetola W (1990). ONA: a revolutionary art movement in commentary Nigeria? Paper presented at the 1990 Conference on Yoruba at the Obafemi Awolowo University, IIe-Ife. April 24-28.

[19] Filani K (1998). Form and Content as a Basis for the Classification of Contemporary Nigerian Arts, USO. Nigerian Journal of Arts, 2(1\&2): 38-42. Google $\underline{\text { Scholar }}$

[20] Federal Department of Culture (1981). NUCLEUS, Lagos.

[21] Chukueggu C and Onwuakpa S (2016). Natural Synthesis and Contemporary Nigerian Visual Arts: An Exposition of Uche Okeke's works. African Research Review: An International MultiDisciplinary Journal, 10 (4): 257-269. Google Scholar; https://doi.org/10.4314/afrrev.v10i4.18

[22] Ikwuemesi K (1996). Nigeria Art and the Politics of Identity, USO: Nigeria Journal of Art, 1(2): 16-18.

[23] Filani K (1998). Form and Content as a Basis for the Classification of Contemporary Nigerian Arts, USO. Nigerian Journal of Arts, 2 (1): 38-42. 